\title{
Práticas jornalísticas e políticas públicas: Estudo dos indicadores de análise das coberturas sobre crianças e adolescentes
}

\author{
Leonel Aguiar* \\ Vinicius Neder**
}

Artigo recebido em: 20 de setembro de 2010

Aprovado em:

7 de outubro de 2010

* Jornalista, doutor em Comunicação pela Universidade

Federal do Rio

de Janeiro (UFRJ)

e professor do

Programa de Pós-

graduação em

Comunicação

Social da Pontifícia

Universidade Católica do Rio de Janeiro

(PUC-Rio).

leonelaguiar@puc-rio.br

** Jornalista, mestre em Comunicação

Social pela Pontifícia Universidade Católica do Rio de Janeiro

(PUC-Rio) e redator do Jornal da Ciência, veículo da Sociedade

Brasileira para o Progresso da Ciência

(SBPC).

vneder@gmail.com
Resumo: Este artigo descreve os resultados de uma pesquisa baseada na análise das coberturas sobre a exclusão social de crianças e adolescentes, destacando alguns pontos de reflexão sobre a relação entre as práticas jornalísticas e as políticas públicas. E enfatizado, sobretudo, o papel da referência às políticas públicas como indicador de uma determinada qualidade da cobertura jornalística, em uma análise de conteúdo comparativa entre o "noticiário cotidiano" e as "reportagens especiais" na mídia impressa. Apesar do maior espaço dedicado à temática dos direitos da infância e de juventude ao longo da década pesquisada, verifica-se que "parâmetros mínimos" da prática jornalística atenta a agenda das políticas públicas para crianças e adolescentes são mais dificilmente atendidos no "noticiário cotidiano" do que nas "reportagens especiais".

Palavras-chave: Jornalismo impresso; políticas públicas; infância.

\section{Journalistic practice and public policies: \\ A study of indicators for analysis of coverage on children and adolescents}

Abstract: This paper describes the results of a analysis upon the coverage about children social exclusion in Brazil, highlighting the relations between journalistic practice and public policies. The emphasis is upon the role of public policies citation (in the stories) as an indicator in the comparative analysis between "day-to-day news" and "special stories", in Brazilian press media, from mid 1990's to mid 2000's. Despite the space increase for themes related to the youth rights among one decade, it seems that "minimum parameters" of the journalistic practice are hardly observed in the "day-to-day press", comparing to the "special stories".

Keywords: Brazilian press media; public policies; childhood. 


\section{Introdução}

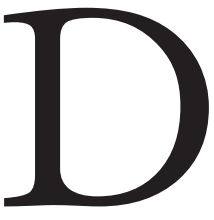

iscutir a prática jornalística sob a perspectiva da imprensa como dispositivo de aprimoramento do Estado democrático é tarefa oportuna no atual contexto histórico brasileiro. O país vive um processo de expansão de sua democracia e as coberturas jornalísticas sobre as "questões sociais"1 assumem importância fundamental à medida que as ações voltadas para o campo social - representadas nas políticas públicas - adquirem posição central.

Nesse contexto, este artigo descreve os resultados de uma pesquisa baseada na análise das coberturas sobre a exclusão social de crianças e adolescentes, com destaque para alguns pontos de reflexão sobre a relação entre a prática jornalística e as políticas públicas. No percurso, visamos adicionar elementos a uma definição de "jornalismo socialmente responsável”, tal como proposto pela Agência de Notícias dos Direitos da Infância (ANDI). Organização nãogovernamental que articula a sociedade em temas vinculados à relação entre mídia e políticas públicas, a ANDI propõe o conceito de "jornalismo socialmente responsável" enquanto prática jornalística voltada para a construção de relatos capazes de contribuir para a inclusão social por meio da promoção de direitos (ANDI, 2003).

Os pontos fundamentais do "jornalismo socialmente responsável” são o foco no desenvolvimento humano e a abordagem contextualizada nos relatos jornalísticos sobre os diversos aspectos da questão social. Para isso, é preciso que as matérias não sejam apenas um simples relato dos acontecimentos. A prática do "jornalismo socialmente responsável”, conforme definida a partir da proposta da ANDI, pode ser resumida em determinados parâmetros que são, simultaneamente, éticos e da técnica jornalística: a pluralidade de fontes - com a busca pelo contraditório -, o banimento de termos pejorativos, a contextualização dos acontecimentos em uma visão social mais ampla, a correta citação das fontes, a utilização dos mecanismos do Estado democrático de direito como referência de garantia básica de cidadania e a referência a políticas públicas, ponto em destaque neste trabalho. Na visão da ANDI, essa prática profissional se constrói com o incentivo aos debates conceituais nas redações e o aprofundamento da formação teórica dos jornalistas (ANDI, 2003).

De uma forma geral, esses parâmetros estão alinhados com o método da objetividade jornalística. Nessa conexão, propomos a ideia de "parâmetros mínimos" como estratégia para identificar a prática do "jornalismo socialmente responsável" numa análise de conteúdo ${ }^{2}$ comparativa entre o "noticiário cotidiano" e as "reportagens especiais". No nível do "noticiário cotidiano", lançamos mão dos monitoramentos de mídia feitos pela $\mathrm{ANDI}^{4}$, para oferecer um panorama da cobertura sobre crianças e adolescentes entre meados da década de 1990 e meados desta primeira década do século XXI. As reportagens

\footnotetext{
"Entende-se aqui "questão social", de forma ampla, como os temas relacionados às desigualdades de renda, de direitos, de status social etc. - observadas na sociedade brasileira.

2 Harold Laswell, em 1927, foi pioneiro na análise de conteúdo sobre a mídia. Na definição de Heloiza Herscovitz (2007, p. 126-127), a "análise de conteúdo jornalística" é um método de pesquisa que analisa textos, sons, símbolos etc., veiculadas em quaisquer suportes midiáticos, a partir de uma amostra (aleatória ou não). Segundo a autora, seu objetivo é "fazer inferências sobre seus conteúdos e formatos" (Idem, p. 127).
} 
especiais foram escolhidas entre as que venceram o Prêmio Esso de Jornalismo, conforme a perspectiva metodológica de Geertz (1978) e sua noção de informante em relação às práticas culturais.

Da comparação, emerge nossa hipótese de pesquisa: a cobertura geral sobre a exclusão social de crianças e adolescentes está em processo de melhoria, conforme os parâmetros mínimos do "jornalismo socialmente responsável", mas mantém-se uma importante diferença entre o material publicado cotidianamente e o material especial. Essa diferença parece ser maior do que o padrão normalmente observado entre matérias factuais e reportagens especiais. Isso indicaria uma dificuldade na disseminação desses "parâmetros mínimos" entre a média dos profissionais.

\section{Pressupostos teóricos}

Tomamos o jornalismo como um dos protagonistas, no âmbito dos meios de comunicação de massa, na construção social tanto da "realidade" cotidiana quanto da "verdade" sobre o mundo real. Obviamente, outros fatores concorrem para essa construção na interação social, mas, desde a instauração do Iluminismo e, posteriormente, a constituição da mídia como "rede que se estabelece entre os discursos heterogêneos da vida pública" e "dispositivo emergente no cruzamento das relações de poder e de saber" (SODRÉ, 2009, p. 112), o discurso jornalístico tem sido um dos principais procedimentos de produção da "verdade".

Como analisamos as coberturas jornalísticas sobre a exclusão social da juventude pelo viés da prática profissional, não podemos deixar de recorrer às correntes teóricas voltadas para o fazer jornalístico, sobretudo as que partem do pressuposto da "realidade como construção social". Esse é o caso da chamada "teoria etnoconstrucionista", ou newsmaking (SCHUDSON, 1978; TUCHMAN, 1978), que segue a linhagem da "sociologia do conhecimento" (BERGER \& LUCKMANN, 2007), partindo da premissa de que o "mundo real” só é acessível por construções sociais - linguísticas, em última análise.

Ao conceituar a realidade como "construção social", assumimos que ela está em disputa. Nessa concepção, a imprensa relata os acontecimentos num processo complexo de interação social, entre "os jornalistas e as fontes de

\footnotetext{
${ }_{3}^{3}$ Seguindo Muniz Sodré (2009) e Nilson Lage (1982) e, ao mesmo tempo, reconhecendo que a definição de "notícia" não é conceitualmente clara, definimos "noticiário cotidiano" como o conjunto de "notícias factuais" que dão conta dos acontecimentos do dia. A distinção entre os gêneros da "notícia" e da "reportagem" está na associação do primeiro a "fatos novos" (LAGE, 1982, p. 35). Também reconhecendo a fluidez do conceito, definimos "reportagem especial" como relatos jornalísticos mais aprofundados sobre os fatos - não necessariamente os do dia.

${ }^{4}$ Com os relatórios Infância na mídia, a ANDI mantém sob monitoramento os principais jornais do Brasil, desde 1996. O crescimento acumulado do espaço destinado pelos jornais ao tema foi de 1.148,74\%, entre 1996 e 2004: saltou de 10.540 para 131.617 inserções (a ANDI considera inserção, com o mesmo peso, cada unidade de texto), levando em conta apenas os 45 veículos brasileiros presentes em todos os relatórios nesse intervalo de sete anos (o número de veículos monitorados variou ano a ano, mas 45 estão em todos os relatórios) (ANDI, 2005, p. 5). De 2005 a 2007, seguiram sob análise 54 veículos no Brasil. Em 2005, foram projetadas 116.556 inserções, a partir de amostra de 9.713. Em 2006, foram projetadas 156.552 inserções (amostra de 13.046). Em 2007, o número foi de 149.640 (amostra de 12.470) (ANDI, 2007, 2009).
} 
informação; os jornalistas e a sociedade; os membros da comunidade profissional, dentro e fora de sua organização" (TRAQUINA, 2001, p. 84-85). Esse processo se dá nas bases de uma cultura profissional, em cujas correntes hegemônicas a objetividade é considerada inerente à prática - ou, pelo menos, um atributo realizável - e, portanto, é o paradigma da "ideologia profissional" dos jornalistas. Num processo histórico iniciado no século XIX, formou-se o que podemos chamar de "ideologia da objetividade", baseada no pressuposto de que os relatos jornalísticos refletem, fielmente, a realidade.

Por outro lado, a perspectiva oferecida pelas correntes teóricas do paradigma da "realidade como construção social" refuta a possibilidade de uma linguagem neutral. Ou seja, a objetividade como antítese da subjetividade do jornalista não é realizável. Isso não significa descartar a objetividade, assumindo-a como uma falácia, mas conceituá-la como um método, oferecendo um olhar crítico sobre a "ideologia da objetividade".

A abordagem histórica de Schudson (1978) nos oferece subsídios nesse sentido, ao dissociar o surgimento da objetividade do advento da notícia e do jornalismo informativo. Muitos manuais de história da mídia tendem a creditar a emergência da objetividade jornalística à criação da agência de notícias Associated Press, em 1848, pouco depois da invenção do telégrafo. Para transmitir via telégrafo relatos para jornais de todos os cantos dos Estados Unidos, a Associated Press adotou estilo de redação conciso, atendo-se aos fatos, e com isso teria introduzido o paradigma informativo e objetivo da notícia.

A perspectiva histórica de Schudson, contudo, refuta o determinismo tecnológico, ao demonstrar que o formato da notícia surgiu nas décadas de 1830 e 1840, quando, num momento de grande desenvolvimento econômico, modernização e urbanização dos Estados Unidos, os jornais começaram a relatar acontecimentos do cotidiano, em vez de apenas difundir opiniões. Nos primeiros relatos, a preocupação com a fidelidade ao mundo real não se colocava. A questão da correspondência dos relatos com a realidade se colocou somente nas décadas de 1920 e 1930, após a Primeira Guerra Mundial. "Nos anos 1920 e 1930, muitos jornalistas observaram com crescente ansiedade que os fatos, ou o que eles tomavam por fatos, não eram confiáveis" (SCHUDSON, 1978, p. 6-7).

Dessa forma, a objetividade jornalística se consolidou nos Estados Unidos como um conjunto de regras e procedimentos para substituir a fé nos fatos num mundo em que nem eles eram confiáveis. "Objetividade, nesse sentido, significa que as declarações de alguém sobre o mundo são confiáveis desde que submetidas a regras estabelecidas e legitimadas por uma comunidade profissional" (SCHUDSON, 1978, p. 7).

As regras seriam estabelecidas ainda na primeira metade do século passado e começaram a ser expressas nos códigos deontológicos desenvolvidos no âmbito das associações profissionais de jornalistas nos Estados Unidos. Os códigos surgiram com a pretensão de oferecer parâmetros éticos para a conduta profis-

\footnotetext{
${ }^{5}$ Aqui se toma ideologia como um "conjunto de ideias" que define o campo profissional. Não estamos, portanto, enveredando-nos pelas diversas correntes teóricas que se empenharam em conceituar o termo.
} 
sional e como uma resposta à constatação da falibilidade dos fatos. Em suma, recomendavam práticas como oferecer espaço e acessos iguais a mais de um ponto de vista, sempre buscar o contraditório (as diversas versões sobre o fato, "o outro lado da história") e atribuir corretamente as informações às fontes.

Essas práticas são citadas por Philip Meyer (1989), em "A ética no jornalismo", como "regras pragmáticas para a objetividade", parâmetros de conduta técnica no exercício do jornalismo, para relatar a realidade a partir da complexidade de pontos de vista que a formam. Ou seja, trata-se de reconhecer que o mundo real não existe independentemente de uma realidade socialmente construída. Assim, a objetividade jornalística é um método de trabalho para enriquecer as subjetividades presentes no relato dos acontecimentos e garantir parâmetros mínimos de qualidade na operação jornalística (PENA, 2007, p. $50-51)^{6}$.

Dessa forma, o que se pretendeu na pesquisa aqui relatada é colocar a prática do "jornalismo socialmente responsável" como um conjunto de "parâmetros mínimos" da objetividade - compreendida como método. A partir daí, verificamos o quanto o "noticiário cotidiano" e as "reportagens especiais" em questão observam esses parâmetros.

\section{O noticiário cotidiano}

Nosso objeto de pesquisa foi recortado em dois planos. Em primeiro lugar, no plano do "noticiário cotidiano", a avaliação geral dos relatórios "Infância na mídia", da ANDI, aponta para avanços importantes na cobertura sobre crianças e adolescentes, tanto quantitativamente (espaço destinado ao tema) quanto qualitativamente. De uma forma geral, as análises publicadas junto a cada edição do relatório apontam a conscientização social dos jornalistas como responsável pelo crescimento do espaço destinado ao tema.

Os critérios e metodologias de avaliação qualitativa foram sendo aprimorados ano a ano. Segundo a ANDI, esse movimento foi imposto pela própria evolução quantitativa da cobertura. O conceito de "busca de soluções" foi o primeiro critério qualitativo, introduzido em 1997. Já então, a referência a políticas públicas consolidou-se como indicador importante, pois os relatórios passaram a indicar as matérias que focalizavam projetos sociais e políticas bem-sucedidos ou a investigação de soluções para as questões que afetam a qualidade de vida de crianças e adolescentes.

O objetivo do critério "busca de soluções" é dar visibilidade a "um jornalismo mais equilibrado entre a denúncia das catástrofes sociais" e a divulgação "das soluções ou das possibilidades de solucionar os problemas dos jovens brasileiros vítimas das desigualdades" (ANDI, 2000, p. 113). No "Infância na mídia" sobre a cobertura do ano 2000, a ANDI passou a classificar também as matérias que continham ótica de "denúncia", sem apresentar caminhos para solucionar a realidade relatada.

"No Brasil, o processo de construção da "ideologia da objetividade" na cultura jornalística hegemônica guarda algumas distinções em relação ao caso norte-americano, conforme destaca Marialva Barbosa (2007). Não entramos aqui no mérito dessas distinções, mas é importante ressaltá-las, sobretudo nas temáticas relacionadas à exclusão social, dadas as particularidades da formação social brasileira. 
Dos critérios da ANDI para tornar tangíveis as avaliações qualitativas sobre a produção da mídia, escolhemos alguns para guiar a análise aqui empreendida. O principal deles é o enfoque - dividido em "busca de soluções", "denúncias" ou "meramente factuais" -, mas neste artigo queremos ressaltar a menção a políticas públicas como forma de enriquecer a análise geral.

Com o critério do enfoque, pretende-se verificar alguma relação entre o caráter puramente factual e a não observância dos parâmetros mínimos já destacados. Quando a ANDI introduziu o conceito de "busca de soluções", em 1997, passou a ser possível medir, de certa forma, o caráter factual da cobertura. Isso pode ser feito ao olharmos o equilíbrio entre o percentual de matérias com enfoque de "busca de soluções" e a parcela com enfoque de "denúncias", pois as inserções não classificadas em nenhuma das categorias são, geralmente, puramente factuais.

A Pesquisa Infância na Mídia não utiliza terminologia específica para identificar as matérias que não se enquadram nos critérios determinados para "Buscas de Soluções" ou "meras Denúncias". Essas matérias - a maior parte factuais não aprofundam a investigação seja sob a ótica das soluções ou das denúncias (ANDI, 2000, p. 113, grifos dos autores).

Para verificar a existência da relação acima descrita, recorremos ao corte temático ${ }^{7}$ das análises da ANDI, numa comparação entre, de um lado, o índice médio de matérias com enfoque em "busca de soluções" e "denúncias", e, do outro, o índice apresentado nas inserções do tema Violência. O percentual de inserções factuais sobre violência é maior do que a média. Isso ocorre até os monitoramentos de mídia referentes ao ano de 2004. A partir de 2005, houve uma mudança de tendência, explicitada a seguir.

Apesar da melhoria qualitativa geral apontada pela ANDI em seus relatórios, a temática da violência manteve-se como uma das áreas de cobertura mais problemáticas. $\mathrm{Na}$ análise temática Balas perdidas, a ANDI (2001) já havia chamado a atenção para o fato. Além da falta de contextualização, os relatórios da ANDI, ano a ano, apontam pouca pluralidade de fontes (dependência excessiva das oficiais, como a polícia) e uso de termos pejorativos como os erros mais recorrentes na abordagem de situações violentas envolvendo crianças e jovens.

Ao longo de 1999, a ANDI monitorou 48.639 inserções em jornais e revistas: $30,83 \%$ delas tinham enfoque na busca de soluções e $11,27 \%$, em denúncias. Do total de inserções, 6.680 eram sobre Violência. Destas, apenas 12,52\% tinham enfoque em busca de soluções e $9,59 \%$ tinham enfoque em denúncias. Portanto, $77,89 \%$ das inserções sobre Violência eram factuais, contra 57,9\%, na média. No monitoramento sobre o material publicado em 2000 (64.396 inserções em jornais e revistas), os índices de busca de soluções e denúncias foram de $31,01 \%$ e $6,96 \%$, respectivamente. No tema Violência, porém, 85,43\% das 14.762 inserções tinham enfoque basicamente factual, contra $62,03 \%$, na

\footnotetext{
7 Os monitoramentos da ANDI classificam as matérias de acordo com temas pré-estabelecidos. Desde 1999, o tema Educação é o mais abordado na cobertura sobre os direitos da infância e da juventude.
} 
média.

Em 2001, 35,6\% das 75.797 inserções monitoradas tinham enfoque em busca por soluções e $8,8 \%$, em denúncias - ou seja, 55,6\% poderiam ser consideradas meramente factuais. Já no tema Violência o enfoque factual respondia por $83,14 \%$ das 15.373 inserções. Em 2002, houve aumento do enfoque factual na média: 60,9\% das 93.581 inserções não apresentavam nem busca de soluções nem denúncias. No tema Violência (15.903 inserções do total), o enfoque factual estava em $73,69 \%$ das matérias.

O padrão seria mantido em 2003 e 2004. Em 2003, 83,65\% das inserções do tema Violência eram factuais, contra $69,75 \%$ na média - nesse ano, apenas $19,76 \%$ das 115.869 inserções tinham enfoque na busca de soluções e 10,49\%, em denúncias. Em 2004, 80,54\% das inserções sobre Violência eram factuais, contra $68,45 \%$ na média - o total de inserções atingiu 161.706 , com 21,2\% dos enfoques na busca de soluções e 10,35\%, em denúncias.

Segundo os relatórios "Direitos, infância e agenda pública” (ANDI, 2007, 2009) - com o monitoramento de mídia referente a 2005, 2006 e 2007 e abrangência ampliada para toda a América Latina - e dados preliminares obtidos para esta pesquisa junto à ANDI, a parcela de inserções com ótica factual cresceu na média e diminuiu no tema Violência. Ou seja, de 2005 a

Para elevar os parâmetros mínimos da cobertura sobre as questões sociais é preciso comprometer a comunidade jornalística 2007, a cobertura sobre violência apresentou-se menos factual do que a média. A mudança deveu-se, principalmente, ao aumento de textos com enfoque nas denúncias.

Em 2005, das 116.556 inserções projetadas, 13,67\% tinham enfoque em "busca de soluções" e 3,79\%, em "denúncias". O tema Violência, que respondeu por $12,3 \%$ do total de inserções, teve 9,63\% delas em "busca de soluções" e 13,10\%, em "denúncias". Ou seja, a parcela de material factual, na média, foi de $82,54 \%$, enquanto, na temática Violência, foi de 78,07\%. Em 2006, das 156.552 inserções projetadas, $15,64 \%$ discutiram soluções e $4,15 \%$ apresentaram denúncias. No tema Violência (11,21\% do total de inserções projetadas), os percentuais ficaram em $14,48 \%$ e $18,17 \%$, respectivamente. A parcela factual ficou, na média, em $80,21 \%$ e, em Violência, em $67,35 \%$. A tendência de inversão manteve-se em 2007. No total de 149.640 inserções projetadas, $21,42 \%$ tinham enfoque em "busca de soluções" e 4,75\%, em "denúncias", resultando em 73,83\% de matérias factuais. Na temática Violência $(12,17 \%$ do total de inserções projetado), $13,63 \%$ dos textos buscavam soluções e $15,01 \%$ apresentavam denúncias. O percentual de material factual ficou, portanto, em $71,36 \%$, pouco abaixo da média.

Contudo, o enfoque é apenas um dos critérios de avaliação qualitativa da cobertura nos monitoramentos da ANDI. Ao longo do tempo, a agência desenvolveu outros instrumentos para medir a qualidade das matérias, sobretudo porque olhar apenas para o enfoque pode resultar em algumas distorções. Um dos problemas do conceito de "busca de soluções" é a influência do uso de veículos de comunicação como instrumento político-partidário. Especialmente nas cidades de menor porte, é comum o jornal - e, geralmente, emissoras de TV e rádio - pertencer a grupos políticos de situação. A ANDI verificou que alguns veículos tinham ótimos índices com enfoque em "busca de soluções" 
porque davam espaço, sem espírito crítico, a programas e políticas dos governos locais.

Para superar esse problema, a solução foi combinar o critério do enfoque com outros indicadores. Nesse rol, a referência a políticas públicas destacase entre outros pontos, como as fontes utilizadas, a referência a legislações e direitos, a menção a estudos e dados estatísticos. Em entrevista ${ }^{8}$, o secretárioexecutivo da ANDI, Veet Vivarta, ressalta que o acompanhamento, a crítica e a discussão sobre políticas públicas por parte da imprensa impõem-se como necessários num quadro em que as temáticas relacionadas aos direitos e à exclusão social de crianças e adolescentes já encontraram seu espaço na agenda jornalística.

O foco de políticas públicas é um diferencial importante para a contextualização da matéria de qualidade. (...) A menção a políticas públicas a gente hoje considera um elemento importante e, se está agregado à busca de soluções, isso significa que se está discutindo as políticas (VIVARTA, 2009).

Como estratégia para nossa análise de conteúdo, sugerimos que a relação entre a ótica de "busca de soluções" e a referência a políticas públicas - indicador captado pela ANDI a partir de 2005 - oferece outro olhar sobre a mudança de tendência no caráter factual das matérias do tema Violência, verificado nos monitoramentos de 2005, 2006 e 2007. O percentual de inserções com menção a políticas públicas no tema Violência ficou sempre aquém da média. Em 2005, ficou em 8,24\%, contra $15,32 \%$, no total projetado de inserções. Em 2006, ficou em 13,11\%, contra 18,47\%. E, finalmente, em 2007, ficou em $7,77 \%$, contra os $16,04 \%$ da média. Os dados sugerem que, apesar dos avanços e da inversão de tendência verificada no caráter factual da cobertura da violência, na média, a imprensa continua tendendo a tratar a violência relacionada aos jovens com viés estritamente factual.

Por fim, se nosso intuito é verificar a relação entre esse viés e a não observância de parâmetros mínimos na prática da imprensa, pode ser interessante, ainda no corte temático da ANDI, mirar o tema Educação. Os avanços nessa temática, tanto em quantidade quanto em qualidade, são maiores do que os do tema Violência. Na cobertura sobre educação também se verificou elevação do nível de matérias factuais. Ele estava em 56,86\% no monitoramento sobre 1999. Foi crescendo até dar um salto, de 2002 para 2003 - de 59,14\% para 68,43\%. De 2004 para 2005, momento da inversão de tendência na temática Violência, houve novo salto, de 70,1\% para 80,65\%. Em 2006, 80,21\% das inserções em Educação poderiam ser consideradas factuais e, em 2007, 71,43\%.

Dessa forma, entre 2005 e 2007, a cobertura sobre educação poderia ser considerada mais factual do que a sobre violência. Quando recorremos mais

\footnotetext{
8 Além dos relatórios de monitoramento de mídia da ANDI e da análise de conteúdo de quatro reportagens especiais, a pesquisa em tela usou como recurso metodológico cinco entrevistas em profundidade, com três jornalistas premiados (Amaury Ribeiro Jr., Sandra Kiefer e Eduardo Auler), com o secretário-executivo da ANDI, Veet Vivarta, e com o professor da Escola de Comunicação da Universidade Federal do Rio de Janeiro Evandro Ouriques, coordenador do curso de extensão Jornalismo de Políticas Públicas Sociais (NEDER, 2009, p. 122-182).
} 
uma vez ao indicador da menção a políticas públicas, porém, a constatação não é tão simples. As inserções classificadas em Educação apresentaram sempre um nível de referência a políticas públicas acima da média: $26,44 \%$, em 2005 (contra 15,32\%, na média, e 8,24\%, em Violência); 20,89\%, em 2006 (contra 18,47\%, na média, e 13,11\%, em Violência); e 20,61\%, em 2007 (contra 16,04\%, na média, e 7,77\%, em Violência), sempre segundo dados da ANDI.

\section{As reportagens especiais}

O segundo plano de nosso objeto de pesquisa é formado por quatro "reportagens especiais": (1) suíte de reportagens sobre criminalidade infanto-juvenil publicada em O Dia, em 1997, de autoria de equipe coordenada por Albeniza Garcia; (2) reportagem sobre exploração sexual de adolescentes em Manaus (AM), do repórter Amaury Ribeiro Jr. e do fotojornalista Luís Carlos Santos, publicada por duas semanas, a partir de março de 1997 no jornal O Globo; (3) série sobre evasão escolar publicada no jornal Extra, de Eduardo Auler, em 2006; e (4) caderno especial assinado pela repórter Ana Beatriz Magno e pelo fotojornalista José Varella, publicado em 12 de outubro de 2007, no Correio Braziliense.

A partir dos critérios de análise da ANDI, captamos três pontos no material empírico: o número de inserções ${ }^{9}$, o número de fontes e o uso do termo pejorativo "menor"10. Com essa escolha, visamos tanto simplificar a análise quanto tentar colocá-la em denominadores comuns à perspectiva da ANDI.

No caso dos termos pejorativos, a evolução nas reportagens especiais entre 1997 e 2007 é clara: enquanto nas coberturas publicadas na década de 1990 o termo "menor" foi usado na razão de 1,97 (O Globo) e de 2 (O Dia) vezes por inserção, na primeira década do século XXI, o índice caiu para 0,16 (Extra) e zero (Correio Braziliense).

Em termos da pluralidade de fontes, as matérias especiais estão num patamar acima da cobertura cotidiana. Na série sobre exploração sexual infantojuvenil publicada em $\mathrm{O}$ Globo, foram citadas 2,14 fontes por inserção. Dez anos depois, as matérias do caderno especial do Correio Braziliense citaram 2,09 fontes por texto. No mesmo ano de 2007, segundo dados da ANDI, o número médio, na cobertura geral, foi de 1,43 fonte por inserção. Um ano antes, em 2006, essa média ficou em 1,38. A série sobre evasão escolar publicada no Extra no mesmo ano citou 1,13 fonte por inserção, mas se usarmos na conta o total de entrevistas feitas por Eduardo Auler - 153, como contou em entrevista (AULER, 2009) -, o índice sobe para 3,55. A exceção é a série de $\mathrm{O}$

\footnotetext{
${ }_{9}$ Adotamos aqui a mesma definição utilizada pela ANDI: todos os textos (matérias principais, boxes, matérias coordenadas ou subordinadas, chamadas na primeira página, artigos etc.) são contados como uma inserção, independentemente da função ou do tamanho.

10 número de inserções visa dar noção do espaço ocupado por cada cobertura analisada. Ao fazer a contagem, faremos um cálculo da razão da primeira sobre a segunda. Sobre as fontes, vale destacar que foram contadas todas as entrevistas citadas em cada inserção. Já a análise sobre o uso do termo pejorativo "menor" pretende identificar indícios, na prática e no discurso jornalísticos, da permanência de traços da exclusão social na formação social brasileira. Termos pejorativos não têm vez na prática do "jornalismo socialmente responsável".
} 
Dia, com 0,7 fonte por matéria.

Reportagens especiais sempre terão maior número de fontes do que matérias cotidianas. Contudo, a pequena variação da razão entre número de fontes e inserções, nos monitoramentos da ANDI - variou de 1,11, em 2002, a 1,43, em 2007 - sugere dificuldade em incorporar a busca do contraditório no jornalismo do dia a dia. Segundo Veet Vivarta, "continuamos tendo na média geral um limite [de fontes]. A média se mantém mais ou menos estacionada entre uma e 1,3 fonte por notícia. A gente acha uma média baixa, mesmo entendendo que parte dessa cobertura é de noticias factuais” (VIVARTA, 2009).

Mesmo considerando situações de mercado que levam à falta de tempo para os jornalistas trabalharem temas complexos como a exclusão social de crianças e adolescentes, Vivarta pondera que, em outras temáticas, os parâmetros mínimos parecem mais elevados (VIVARTA, 2009). Nesse sentido, vale lembrar que o uso de termos pejorativos raramente se coloca na cobertura de economia. Tampouco se vê, no jornalismo econômico, tamanho desconhecimento das legislações e do funcionamento das instituições, como verificamos na cobertura sobre exclusão social. Isso está expresso nos constantes usos de termos já não existentes, como “juiz de menores”, “Juizado de Menores”, entre outros. Quando o Departamento de Aviação Civil (DAC) foi substituído pela Agência Nacional de Aviação Civil (Anac), em 2006, os jornais adotaram a nova nomenclatura quase instantaneamente.

\section{Considerações finais}

A análise comparativa aqui resumida sugere que, no plano da cobertura geral e nos temas mais factuais, como é o caso da violência envolvendo crianças e adolescentes, observam-se menos frequentemente "parâmetros mínimos" da prática jornalística, incluindo a atenção às políticas públicas do setor na produção do noticiário. Em outras áreas da cobertura, como a educação, abordagens mais plurais têm encontrado espaço na passagem do século XX para o XXI. Vale destacar a importância, nas análises de conteúdo, do foco nas políticas públicas para as conclusões sugeridas.

Se, no plano das reportagens especiais, parece-nos evidente o aumento da atenção a parâmetros mínimos do “jornalismo socialmente responsável”, entre 1997 e 2007 (pelo menos nos três pontos aqui analisados), para elevar os parâmetros mínimos da prática nas coberturas sobre as questões sociais é preciso comprometer a comunidade jornalística nessa discussão.

Esses parâmetros estão dados e sua elevação passa pela incorporação das políticas públicas na pauta jornalística. Nossa análise comparativa sugere que, frequentemente, a conquista de mais espaço e a melhoria da cobertura da imprensa sobre a questão da desigualdade e exclusão social de crianças e adolescentes são resultados de esforços individuais de jornalistas atentos as políticas públicas setoriais, geralmente autores das matérias especiais. 


\section{Referências bibliográficas}

AGÊNCIA DE NOTÍCIAS DOS DIREITOS DA INFÂNCIA. Infância na mídia: uma pesquisa. Coordenação da pesquisa Marco Túlio Alencar. Brasília: ANDI/Instituto Ayrton Senna, 2000.

. Balas perdidas: um olhar sobre o comportamento da imprensa brasileira quando a criança e o adolescente estão na pauta da Violência. Brasília: ANDI/ Departamento da Criança e do Adolescente/Associação de Apoio à Criança e ao Adolescente, 2001c.

. Que país é este? Pobreza, desigualdade e desenvolvimento humano \& social no foco da imprensa brasileira. Coordenação Veet Vivarta. São Paulo: Cortez, 2003a.

. Infância na mídia. Ano 10, número 14. Brasília: ANDI/Instituto Ayrton Senna, 2005.

. Direitos, infância e agenda pública: uma análise comparativa da cobertura jornalística latino-americana. Brasília: ANDI, 2007.

. Direitos, infância e agenda pública 2005-2007: uma análise comparativa da cobertura jornalística latino-americana. Coordenada por Veet Vivarta; traduzido por Sandra Pérez. Brasília: ANDI; Rede ANDI América Latina, 2009.

AULER, Eduardo. Entrevista concedida a Vinicius Neder. Rio de Janeiro, 27 ago. 2009.

BARBOSA, Marialva. História cultural da imprensa: Brasil, 1900-2000. Rio de Janeiro: Mauad X, 2007.

BERGER, Peter; LUCKMANN, Thomas. A construção social da realidade: tratado de sociologia do conhecimento. 27.ed. Petrópolis: Vozes, 2007.

GEERTZ, Clifford. A interpretação das culturas. Rio de Janeiro: Zahar, 1978.

HERSCOVITZ, Heloiza Golbspan. Análise de conteúdo em jornalismo. In: LAGO, Claudia \& BENETTI, Marcia. Metodologia de pesquisa em jornalismo. Petrópolis: Vozes, 2007.

LAGE, Nilson. Ideologia e técnica da notícia. 2 ed. Petrópolis: Vozes, 1982. MEYER, Philip. A ética no jornalismo: um guia para estudantes, profissionais e leitores. Rio de Janeiro: Forense Universitária, 1989.

NEDER, Vinicius. Jornalismo e exclusão social: análise comparativa nas coberturas sobre crianças e adolescentes. 2009. $182 \mathrm{f}$. Dissertação (Mestrado em Comunicação Social). Pontifícia Universidade Católica do Rio de Janeiro, Rio de Janeiro, 2009.

PENA, Felipe. Teoria do jornalismo. São Paulo: Contexto, 2007.

SCHUDSON, Michael. Discovering the news: a social history of American newspapers. Nova York: Basic Books, 1978.

SODRE, Muniz. A narração do fato: notas para uma teoria do acontecimento. Petrópolis: Vozes, 2009.

TRAQUINA, Nelson. O estudo do jornalismo no século XX. São Leopoldo: Editora Unisinos, 2001.

TUCHMAN, Gaye. Making news: a study in the construction of reality. New York: The Free Press, 1978.

VIVARTA, Veet. Entrevista concedida a Vinicius Neder. Rio de Janeiro, 3 set. 2009. 